\title{
Inclusive Sustainable Development in the Caribbean Region: Social Capital and the Creation of Competitive Advantage in Tourism Networks
}

http://doi.org/10.21272/bel.4(3).119-126.2020

Babu George, ORCID: https://orcid.org/0000-0002-2791-828X

$\mathrm{PhD}$, Professor and Associate Dean, School of Business, Christian Brothers University, Memphis, TN, USA

Abstract

In the mainstream parlance, tourism is constructed as conspicuous consumption for the exclusively chosen few. Historically, the term "inclusive" in the tourism industry was exclusively used with all-inclusive tourism. All-inclusive tourism is often quite an unethical approach and is probably the antithesis of inclusive development. Likewise, traditional definitions of sustainable tourism, too, did not stress enough of inclusiveness. The focus of sustainable tourism has been to ensure the sustenance of nature and culture and inclusiveness was just one of the conditions that would support this. This paper attempts to blueprint the idea of inclusive, sustainable tourism - which brings inclusion to sustainable development. Inclusion in the cooperative governance framework activates social capital and thereby, tourism businesses can gain lasting competitive advantage. A special mention about the challenges being faced by the Caribbean tourism destinations is given during the discussion. Caribbean tourism is criticized for its powerful thrust for everything that is unsustainable. The "third way" is gaining traction, but it also excludes certain important voices and stakeholders. For the Caribbean region, ending the Sun-Sea-Sand-Sex model of tourism altogether, all of a sudden is not only impractical but also unsustainable. So, the solutions should reform it with more and more inclusivity and sustainability elements. There is still hope, with a new generation of entrepreneurs armed with a combination of idealism survival spirits. Tourism is now at the center of the inclusive economic development paradigm in the Caribbean, more than ever before. During the discussion, certain myths about inclusive, sustainable tourism are demolished, too: say, it is not who controls tourism but how it is controlled which determines inclusiveness and sustainability; also, there is evidence emerging which indicate that even large scale private enterprises could advance inclusiveness and sustainability provided these results in their competitive advantage and increased profitability; finally, inclusiveness does not necessarily mean sustainability or vice versa.

Keywords: Inclusive Sustainable Tourism, Ethics, Social Responsibility, Culture, Competitive Advantage, Cooperative Networks, Policy Framework.

\section{JEL Classification: M14, Z32.}

\section{This work is licensed under a Creative Commons Attribution 4.0 International License}

Cite as: George, B. (2020). Inclusive Sustainable Development in the Caribbean Region: Social Capital and the Creation of Competitive Advantage in Tourism Networks. Business Ethics and Leadership, 4(3), 119-126. http://doi.org/10.21272/bel.4(3).119-126.2020.

(C) The Author, 2020. This article is published with open access at Sumy State University.

\section{Introduction}

By its staple definition, sustainable tourism insists only upon the bare minimum requirement that it should sustain. What it should maintain is open to interpretation. Not every form of sustainable tourism is inclusive in the real sense of the term. In practice, sustainable tourism takes care of the need for only a minimal number of stakeholder constituencies to be included. Community-based tourism (CBT) is proposed as a solution for inclusivity of the most important stakeholder group, the tourism destination community. Even as this highlights the inclusion of the destination locals, the CBT model is criticized for its over-romanticized lopsided vision that local communities are everything. Moreover, CBT agenda often boils down to the economic developmental concerns of those members in a destination community interested in the tourism business.

The inequality in the world is on an ever-increase and every business needs to be inclusive. Tourism has a much more significant role to play in this regard, given the fact that it is often projected as an activity of exclusiveness (Scheyvens \& Biddulph, 2018). No wonder inclusive tourism development has become a hot 
area of scholarly inquiry (Rogerson \& Rogerson, 2020). By definition, inclusive, sustainable development is balanced and equitably distributed economic growth coupled with preserving natural and cultural resources (Lawson, 2010). A balanced set informs our proposal for inclusive, sustainable tourism (IST) of concerns for nature, society, and the economy. Inclusivity stresses poverty alleviation as a goal of economic development (Rauniyar \& Kanbur, 2010), whereas sustainable development theory is often blamed for downplaying economic growth for environmental concerns (Gupta, Pouw \& Ros-Tonen, 2015). It also embraces accessible tourism ideals - both for tourists needing special assistance and for tourism entrepreneurs and job seekers with disabilities. Inclusivity, as per IST implies the harmonious coexistence of all actors and not just the locally rooted tourism business interests.

The Caribbean tourism industry has a history of exploitation and this needs to change. In this paper, a rationale for inclusive, sustainable development through tourism is proposed. It is argued that sustainability without inclusiveness is nothing more than a marketing trick. Likewise, inclusiveness without sustainability could be very exploitative upon nature. Social capital, the bond that holds community members together with their ecosystem, could be leveraged to bring about inclusive sustainable development. A blueprint for this is presented in the particular case of tourism in the Caribbean.

\section{Methodology}

This paper is framed as a systematic literature review based conceptual paper. Several of the studies referenced in it, however, are primary data driven research undertaken by the present author previously. An extensive range of literature related to community development, sustainability, and tourism were reviewed in an iterative manner to develop this paper. The cited literature included peer reviewed scholarly articles, professional trade publications, and data sources from governments and nonprofits. The interpretations included in it also draw from prior interviews conducted by the author for various associated projects in community development and the Caribbean tourism.

Inclusive Sustainable Tourism. Given below in Figure 1 is a model of community-based tourism focused on sustainability and inclusiveness, based on the previous research by this author (see Figure 1).

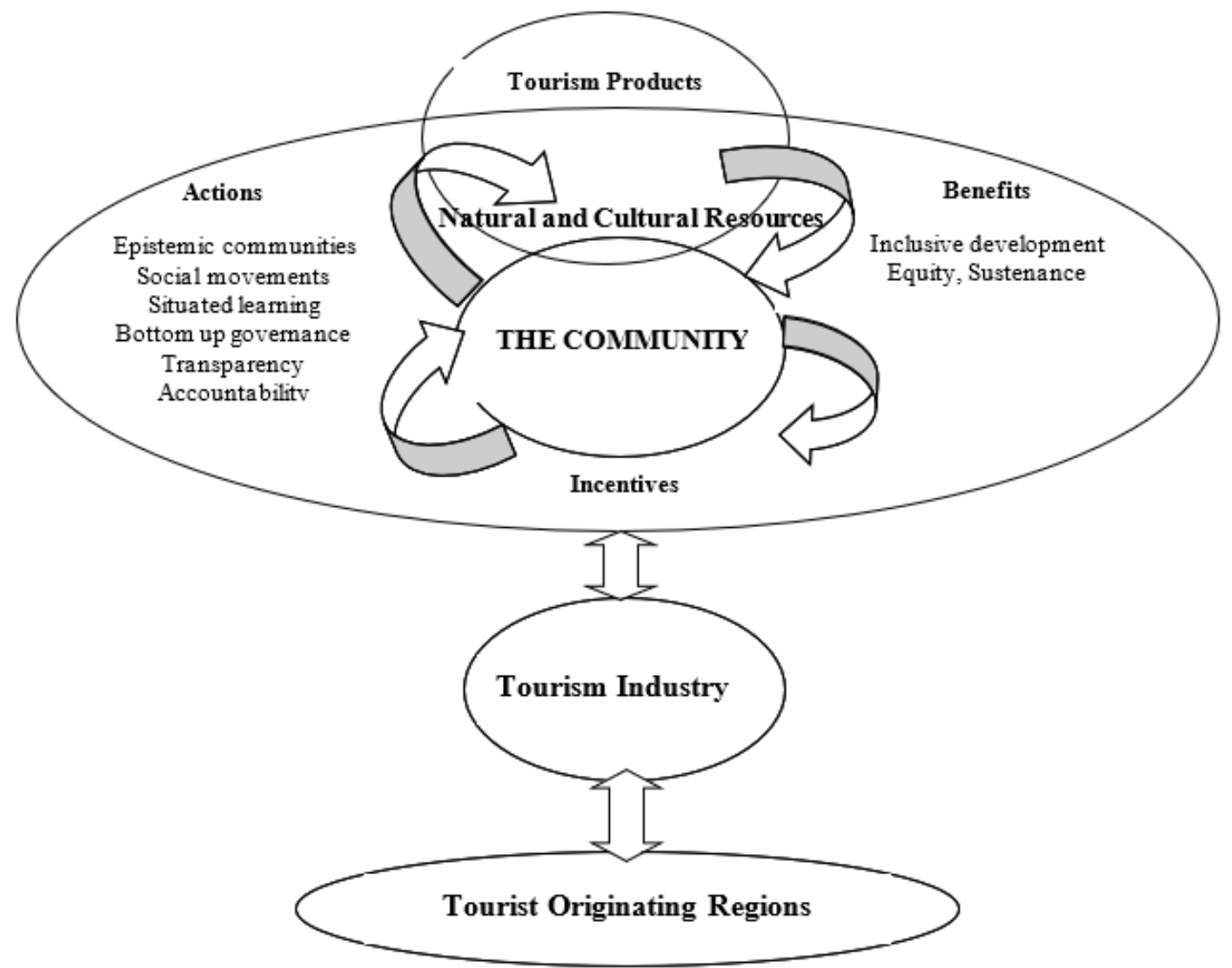

Source: Compiled by the author

Figure 1. A model of inclusive sustainable tourism 
The growth of the community-centered tourism is out of a recognition that it is a tactic used by tourism planners to organize communities to act to expand the reach of the industry's offerings (Dangi \& Jamal, 2016). The goal is to promote socio-economic opportunities and added value for local and foreign tourists. This process opens new niches for destinations, particularly natural, cultural and adventurous destinations. It is the political goal of creating an egalitarian culture in the industry where communities engage and share in the success of the industry and spread a long-standing view of tourism as a wealthy exploiter of which only the rich can take advantage. The development of the community spirit enables individuals to be more informed of the value of their community assets - culture, heritage, food and lifestyle. It mobilizes them to transform these into revenuegenerating ventures while offering tourists a more dynamic and meaningful experience. Through communitycentered business models, tourist destination residents learn to manage small businesses, improve the environment, produce goods, and deal with the market's vagaries. This type of tourism centered on people promotes a sense of ownership that is good for the sustainability of the industry, people's wellbeing, and the preservation of nature and natural resources (Korstanje \& George, 2020). In inclusive, sustainable tourism, ecological, social, economic and cultural sustainability are considered. The community is guided and run to encourage visitors to learn about the culture and the local way of life without removing fringe elements. The community governs it. All types of IST goods, including current categories such as ecotourism, agricultural sector, cultural tourism and heritage tourism, are subject to the need to promote them with the spirit of collective awareness, inclusion and support.

The Crisis of the Caribbean Tourism. The Caribbean zone includes the Caribbean Sea, the islands, and the coast (Mintz, 1983). The region is located southeast of the Gulf of Mexico and the North American mainland, east of Central America and north of South America. The area contains around 700 islands and many other small land types, such as islets, beaches, and cays. The Caribbean is an arbitrary classification (Conway, 1998). According to a generally agreed notion, the countries in the Caribbean include Anguilla, Antigua and Barbuda, Aruba, Bahamas, Barbados, British Virgin Islands, Cayman Islands, Cuba, Dominica, Dominican Republic, Grenada, Guadeloupe, Haiti, Jamaica, Martinique, Montserrat, Netherlands Antilles, Puerto Rico, Saint Barthelemy, Saint Kitts \& Nevis, Saint Lucia, Saint Martin, Saint Vincent, Trinidad \& Tobago, Turks \& Caicos Islands, and US Virgin Islands (Henthorne, George \& Miller, 2016).

Most Caribbean islands are remote, the population is poor and natural resources are very limited for development: Due to their 'exotic' location and proximity to rich North America, cruise tourism has become a natural option for them to grow economically (McElroy \& De Albuquerque, 1998). Their reliance on cruise tourism dollars is so strong that ecological and esthetic capacity is often exceeded, although policymakers consider it 'normal' (Griffin, 2016; Almeyda \& George, 2020). According to Wood (2000), Caribbean tourism can be viewed as a microcosm of globalization at sea. This, however, only complicates the analysis of Caribbean tourism. Topics to be addressed in a substantive study of tourism in the Caribbean region are the deep economic dependency on tourism, the inequity of power ties between the various stakeholder groups and the lack of developed cooperation within this fractured area of the culturally diverse islands (Henthorne \& George, 2009; Lester \& Weeden, 2004).

Since the mid-20th century, worldwide tropical islands have started to shift from colonial export stacks to famous tourism destinations and the Caribbean has taken the lead in this region (Barker, 1998). The Caribbean region is made up of relatively homogeneous micro-states of similar size, socio-cultural history, and natural forms, which have led to the emphasis on mass production of tourist experiences. It is no wonder that the key economic activity of the island nations was mass tourism items for cruising visitors. Yet the tendency towards mass tourism focused on scarce resources contributed to high rates of environmental abuse and degradation; an unsustainable burden at the cost of intergenerational wealth on short term prospects (Parry, Sherlock \& Maingot, 1987). According to McElroy and De Albuquerque (1998), the tourism penetration index is substantially higher for small Caribbean islands than in average countries of comparable sizes. Mass customization is a possible solution to this crisis (Piore \& Sable, 1984). However, authors like Poon (1990) posited that The Caribbean islands are not suitable for versatile tourism industry specialization.

Caribbean tourist destinations are increasingly realizing the need to fight together for the tourist. The Caribbean Tourism Organization (CTO) has been encouraging member nations to identify elements that make each of them unique so that marketing dollars are not wasted in competing against one another (Hill \& Lewis, 2015). For the mass tourist, the Caribbean is still a single, mostly indistinguishable, region. The geography and climate in the Caribbean region vary, but not so much distinguishable to the gaze of the touristic eyes. National destination management organizations and tourism industry bodies of each country in the Caribbean have struggled hard to differentiate their state from all others, but again with not so much success (Croes, 2006). 
Since the early 2000s, the Sun-Sea-Sand-Sex model of tourism in the Caribbean began to face significant challenges (Henthorne, George \& Smith, 2013; Weiler \& Dehoorne, 2014). A few destination countries in the Caribbean anticipated this and began searching for a competitive advantage elsewhere (de Holan \& Phillips, 1997). Authors like Poon (1998) and Henthorne \& Miller (2003) urged that the only way the Caribbean can sustain its tourism in the 21 st century is through innovations in products and processes. However, these searches did not result in the identification of any radically innovative products and the workable alternative for most of these destinations was to concoct some uniqueness in the commonness (Mosedale, 2006). For many destinations, this meant interpreting and reinterpreting the value of tourism resources until that process resulted in identifying something unique (Chambers \& McIntosh, 2008). Based on such sought and found ideas, these destinations unleased various promotional campaigns (Croes, 2006). The experiments in the Unique Selling Proposition (USP) based marketing, however, did not have ultimate success, as the finding of the research by Henthorne, George, \& Miller (2016) indicate. The USP campaigns were driven by short term commercial considerations and largely failed to recognize the community element that should have been the focus of any sustained success stories.

Characteristics of an Inclusive Sustainable Tourism Project. Sustainable community-based tourism should encompass a range of activities that collectively contribute to balanced conservation and development. Some of the most noteworthy characteristics of such projects are listed below (adapted from TPDCO, 2005):

$>$ It should not damage the environment while enhancing the experience of guests and locals, in a sustainable manner.

$>$ It should provide social and economic benefits while minimizing social and economic costs.

$>$ It should satisfy tourists without hurting the local community's collective interests.

$>$ It should find harmony and synergy between sustainability and marketability.

$>$ Who owns it does not matter as much as how the ownership rights are exercised.

> It should implement management systems the performance of which will have to be evaluated based on the sustainability surplus the system brings in.

$>$ Long term view, rather than quarterly profits, must guide the business decisions.

$>$ Constant monitoring of ecological changes is needed to ensure that interventions could be timed adequately well.

$>$ Local community members and the visitors should be educated in sustainable attitudes. Scientific strategies for behavioral modification could be employed.

The IST product developers must ask the following questions from the first stage of idea generation:

Will there be a tradeoff between visitor experience and environmental preservation?

What will be the role of the community (development, operations, management oversight)?

What are the socio-economic benefits and the environmental costs? Is there an environmental benefit?

Will ethical and legal guidance for responsible conduct be adhered to?

Will the thrust on inclusiveness and sustainability enhance the competitiveness of the project?

The International Centre for Responsible Tourism (ICRT) at the University of Greenwich, UK, has prepared a list of causes for the failures of such projects:

$>$ A failure to understand the delicate balance between economic viability and environmental sustainability (If locals do not get to make a decent living, they will seek more exploitative opportunities. Profit is not necessarily evil).

$>$ Failure to create an ecosystem of health interdependence among different stakeholders.

Make ways to keep tourists buy products and services locally. Make them stay longer.

$>$ Minimize capital intensive projects.

$>$ Do not tie conservation expenses with profits from tourism. It will avoid the double trap of conservation being supported by exploitation.

Social Capital for Disaster Recovery and Destination Resiliency. The term social capital was first used in the 1980s by Bourdieu and Coleman (Bourdieu and Coleman, 1991). Social capital is the raw material of civil society (Coleman, 1988). It is created from the myriad of everyday interactions between people. It is not located within the individual or the social structure, but in the space between people (Lochner, Kawachi and Kennedy, 1999). It is not the property of the organization, the market or the state, though all can engage in its production. Social capital is a 'bottom-up' phenomenon. It originates with people forming social connections and networks based on trust principles, mutual reciprocity, and norms of action. Grootaert (1998) suggests that social capital is an essential influence on economic policies and outcomes. For some researchers, this means 
the social groups and networks that produce positive results, while for others, it means the results themselves (Foley \& Edwards, 1997).

Social capital bonds, bridges, and links individuals and institutions in society (OECD, 2001). To possess social capital is to relate with others in society. Portes (1998) suggests the four motivations of bounded solidarity, reciprocity exchange, value introjection, and enforceable trust as fundamental to social capital development. Bounded solidarity refers to the mechanism whereby people in a typical situation learn to identify and support each other's initiatives. Reciprocity exchange is the accumulation of obligations from others according to the norms of reciprocity. Value introjection means an obligation that an individual has got to behave in a particular manner. In the case of an enforceable trust, the expectation of repayment is not based on the recipient's knowledge but both individuals' presence in a social structure (Portes and Landolt, 1996). Gold (1995) provides evidence to the fact that it is social capital that helps minority communities to maintain their integrity. Another noteworthy study (Heller, 1996) on social capital has the state of Kerala in India as its region of study. The Kerala model of development is unusual in that despite the mediocre economic performance, the state's social indicators are at par with the world's best.

The present author provides valuable evidence that social capital can significantly aid in disaster recovery efforts (George, 2007). More significant social capital means greater community support resiliency of the community in the aftermath of calamities. Post-disaster response in terms of assistance to recovery by the local community is conditioned more by pre-disaster factors than by immediate disaster impacts. If the local community's collective spirit worked against recovery in a particular place, it was due to the difference in recovery goals as perceived by the locals and those responsible for the recovery programs (governmental and non-governmental funding agencies). It could be treated as an adaptive response to a unique opportunity to teach the antagonistic enemy a lesson. Social capital shall bond the community together in such an instance.

A Policy Framework for IST. Today, the imperatives for an inclusive model for sustainable tourism are more significant than ever. Towards this, what could governmental and intergovernmental agencies do? The essential question is: "Does our current governance structure permit a modern, innovative and specific policy designed to build networks and alliances focused on the ideology of inclusion in small-and medium-sized tourism and, if so, how?"

According to Agenda 2010 for Small Businesses in the 'World's Largest Industry', released by the UK Presidency Conference 2020, the following are some of the key recommendations:

1. Codify and communicate the existing and emerging best practices about tourism networks and cooperative alliances.

2. Promote sustainable business practices and sustainable development.

3. Enhance business support systems for inclusive and sustainable growth.

4. Deploy informational and communication technologies in a manner as to increase sustainability.

5. Make quality the centerpiece of production and service.

6. Recognize that tourism networks might need external financial support to weather the sunk costs associated with developing certain sustainable practices.

7. Give a level playing field for small and large businesses by instituting equitable regulatory and control systems.

8. Create opportunities for fair dialogues within the tourism system.

9. Invest in SME employee training and organizational development.

10. Invest in data gathering, analysis, and sharing of findings for data-driven decision making.

These ideas may be developed into a policy framework after due dialogues with the representatives of the concerned groups.

Network Advantage in Inclusive Sustainable Tourism. While small local businesses are promoted, the question of whether they can thrive in a more dynamic and globalized world, by referencing the concept of alliances, is addressed affirmatively (Gartner, 1999; Shaw, 2014). Experts have expressed serious doubts about the professed altruistic and pro-people position of governments (van der Zee \& Vanneste, 2015). Nine out of ten grassroots movements were considered on average as illegal and government-suppressed, according to Fox \& Brown (1998). The research shows that tourism SMEs have joined hand and built networks to leverage 
control against the forces that exist. Caribbean tourism has little difference. The influence of such networking is clear, at least in some respects, in the marketing strategies of governments and DMOs.

More living systems than machines are touristic products, particularly eco-cultural products. Theme parks can be viewed more effectively through dominance and power. But it is through involvement in the mutual sense cycle to understand more nature-based goods, which involve cooperative partnerships as critical characteristics (Weidenfeld, 2013). A traditional mediator whose theory, purpose, view and behavior may well adulterate the authentic travelers' experience (George \& George, 2005; Strobl \& Peters, 2013). It will help preserve the authentic spirit of tourist experience by disintermediating these intermediaries and replacing them and localbased co-operatives of small business owners. Where the reality of the USP claims or marketing acts in general have been established in some of the Caribbean destinations, the strength of the negotiating power of the 'thirdway powers' in their sense has succeeded.

Cooperatives as the Governance Framework for IST. In the tourism literature, cooperative networks and other social initiatives, which can generally be included in the third form of growth banner, have been thoroughly explored (Aref \& Gill, 2009; George, 2007a; George, 2007b; McGehee \& Meares, 1998). Cooperative networks established by the community members have created what can be described as a tourist renaissance, particularly in small rural communities. The vision for growth in tourism of these networks has emerged from a collaborative process involving various stakeholders. This mechanism is incorporated into the social capital system, which unites these interest groups.

Networking systems are wide-ranging (Lemmetyinen \& Go, 2009; March \& Wilkinson, 2009; Terpstra \& Simonin, 1993). Four features illustrate the difference between these arrangements: scope, shape, fashion, and motive. Size refers to the comprehensiveness and territorial scope of an Alliance. The shape differs between non-equity deals and the reverse when members of the partnership purchase equity interests in other members. The third element, the fashion, defines the essence of the ties between the members, implicitly and extrinsically. Motives refer to the underlying reason for the creation of an alliance. The concentrated control of financial capital, usually capitalist, establishes the industrial hierarchical systems that are inherently exploitable (Foucault, 1982). On the other hand, involvement in sustainable growth depends on social capital as a partnership. Numerous cases of wealthy social capital groups pursuing inclusive, sustainable development are recorded in this study (Schulman \& Anderson, 1999; Tregear \& Cooper, 2016; Woodhouse, 2006).

Cooperative organizational systems in low social capital environments are not unlikely. In tourism, it is understood that cooperative networks are established as a vital adaptation mechanism by capitalist interests. The reconciliatory atmosphere of the networked model will allow operating companies to conceal their unsustainable activities. A further challenge that may hinder genuinely inclusive growth is the drawback of inappropriate use of social capital by better-connected network participants. Levien's (2015) research in India shows how in a farmers' group, gains are collected at the detriment of fellow villagers. It is necessary to establish checks and balances to prevent society's dominant injustice from masking itself as social capital.

\section{Conclusion}

Inclusive development is crucial to social innovations that benefit the disenfranchised ones and promotes communities' overall wellbeing (Heeks, Foster \& Nugroho, 2014). The main benefits of IST consist of the following: creation of jobs, reducing poverty, having less impact on the culture and environment in an area than mass tourism, building capacity and fellowship in the community, bridging the gap between the core and peripheral communities and making income available to maintain or enrich the cultural resources of the community. The focus of IST is on developing appropriate social enterprise models (Biddulph, 2018). Yet, it is to be understood that IST is not a revolution against larger businesses in the tourism industry. Even larger MNCs could advance inclusivity and sustainability (Zapata Campos, Hall \& Backlund, 2018).

Forming pro-inclusive-development epistemic communities (e.g., tourism cooperative networks) is an essential first step in inclusive development. If there are underlying inequalities in the existing social relations, social capital will be permeated with the same. It is essential to correct aberrations before leveraging social capital - or benefits of growth will be appropriated by those who are privileged in the network of social relationships. The State's governance mechanisms should support the process of community cooperative network building by offering suitable facilitating conditions (Menon, Edward \& George, 2017). Information and communication technologies available to us, mainly social media technologies, permit the traditionally marginalized members of such communities through interactive governance opportunities. Social media technologies, correctly applied, would help boost this purpose (Sarkar \& George, 2020). Investing in technologies, thus, has a lasting impact (Mansell \& Wehn, 1998). 
This paper mainly focused on the positive side of the issue, even though the attempt was not to say inclusive, cooperative networks will resolve all the problems. While admitting our own bias, the myopic attitude of the tourism research community, a kind of institutionalized inertia, towards anything other than the traditional forms of tourism development has made research scarce in tourism cooperatives. We are still far from being able to offer a sufficiently precise and comprehensive framework for the design, development, and management of diverse forms of alliances and networks attuned for inclusive growth (George, McGahan \& Prabhu, 2012; Kireyev \& Chen, 2017). More research is needed to understand the nuanced context-bound ground realities better and construct guidelines for good practice.

Funding. There is no funding for this research.

\section{References}

1. Almeyda, M., \& George, B. (2020). Customer-Based Brand Equity for Tourist Destinations: A Comparison of Equities of Puerto Rico and the US Virgin Islands. Journal of Spatial and Organizational Dynamics, 8(2), 148-172. https://doi.org/10.1163/157180894x00124.

2. Aref, F., \& Gill, S. S. (2009). Rural tourism development through rural cooperatives. Nature and Science, 7(10), 68-73. https://doi.org/10.4337/9781784719388.00010.

3. Biddulph, R. (2018). Social enterprise and inclusive tourism. Five cases in Siem Reap, Cambodia. Tourism Geographies, 20(4), 610-629. https://doi.org/10.1080/14616688.2017.1417471.

4. Dangi, T. B., \& Jamal, T. (2016). An integrated approach to "sustainable community-based tourism". Sustainability, 8(5), 475. https://doi.org/10.3390/su8050475.

5. Foucault, M. (1982). The subject and power. Critical inquiry, 8(4), 777-795. https://doi.org/10.1086/448181.

6. Fox, J. A. \& Brown, L. D. (1998). The struggle for accountability: The World Bank, NGOs, and grassroots movements. MIT press. https://doi.org/10.1177/030437549201700202.

7. Gartner, W. C. (1996). Tourism development, principles, processes and policies. New York, NY: Van Norstrand Reinhold. https://doi.org/10.1016/s0278-4319(97)89043-3.

8. George, B. P. (2007a). Alleppey tourism development cooperative: The case of network advantage. The Public Sector Innovation Journal, 12(2), 1-10. Available at: https://www.innovation.cc/casestudies/2007 1229 george alleppey tourism.pdf.

9. George, B. P. (2007b). Local community's support for post-tsunami recovery efforts in an agrarian village and a tourist destination: a comparative analysis. Community Development Journal, 43(4), 444-458. https://doi.org/10.1093/cdj/bsm019.

10. George, B. P. (2015). What Could Tourism Do to a Small Fishing Village: A Case Study of the City of Weihai, China. Revista Turismo: estudos e práticas, 4, 85-97. https://doi.org/10.5353/th_b3126101.

11.George, G., McGahan, A. M., \& Prabhu, J. (2012). Innovation for inclusive growth: Towards a theoretical framework and a research agenda. Journal of management studies, 49(4), 661-683. https://doi.org/10.1111/j.1467-6486.2012.01048.x.

12.Gupta, J., Pouw, N. R., \& Ros-Tonen, M. A. (2015). Towards an elaborated theory of inclusive development. The European Journal of Development Research, 27(4), 541-559. https://doi.org/10.1057/ejdr.2015.30.

13.Heeks, R., Foster, C., \& Nugroho, Y. (2014). New models of inclusive innovation for development. Innovation and Development, 4(2), 175-185. https://doi.org/10.4324/9781315673479.

14.Henthorne, T. L., George, B. P., \& Miller, M. M. (2016). Unique selling propositions and destination branding: A longitudinal perspective on the Caribbean tourism in transition. Turizam: medunarodni znanstveno-stručni časopis, 64(3), 261-275. https://doi.org/10.1177/146879760200200209.

15.Kireyev, M. A. P., \& Chen, J. (2017). Inclusive Growth Framework. International Monetary Fund. https://doi.org/10.5089/9781484302156.001.

16. Korstanje, M. E., \& George, B. P. (2020). Education as a Strategy to Tackle Over Tourism for Overtourism and Inclusive Sustainability in the Twenty-First Century. Overtourism, 341-359. Palgrave Macmillan, Cham. https://doi.org/10.1007/978-3-030-42458-9_18.

17.Lawson, V. (2010). Reshaping economic geography? Producing spaces of inclusive development. Economic Geography, 86(4), 351-360. https://doi.org/10.1111/j.1944-8287.2010.001092.x.

18.Lemmetyinen, A., \& Go, F. M. (2009). The key capabilities required for managing tourism business networks. Tourism Management, 30(1), 31-40. https://doi.org/10.1016/j.tourman.2008.04.005.

19.Levien, M. (2015). Social capital as obstacle to development: brokering land, norms, and trust in rural India. World Development, 74, 77-92. https://doi.org/10.1016/j.worlddev.2015.04.012. 
20.Mansell, R., \& Wehn, U. (1998). Knowledge societies: Information technology for sustainable development. United Nations Publications. https://doi.org/10.1080/00213624.1999.11506206.

21.March, R., \& Wilkinson, I. (2009). Conceptual tools for evaluating tourism partnerships. Tourism management, 30(3), 455-462. https://doi.org/10.1016/j.tourman.2008.09.001.

22.McGehee, N. G., \& Meares, A. C. (1998). A case study of three tourism-related craft marketing cooperatives in Appalachia: Contributions to community. Journal of Sustainable Tourism, 6(1), 4-25. https://doi.org/10.1080/09669589808667299.

23. Menon, S., Edward, M., \& George, B. P. (2017). Inter-stakeholder collaboration in event management: a case study of Kerala Travel Mart. International Journal of Leisure and Tourism Marketing, 5(4), 370-386. https://doi.org/10.1504/ijltm.2017.10008335.

24.Rauniyar, G., \& Kanbur, R. (2010). Inclusive development: Two papers on conceptualization, application, and the ADB perspective. Manila: Asian Development Bank. https://doi.org/10.1080/13547860.2010.517680.

25.Rogerson, C. M., \& Rogerson, J. M. (2020). Inclusive tourism and municipal assets: Evidence from Overstrand local municipality, South Africa. Development Southern Africa, 18(1), 1-15. https://doi.org/10.1080/0376835x.2020.1796597.

26. Sarkar, S. K., \& George, B. (2018). Social media technologies in the tourism industry: an analysis with special reference to their role in sustainable tourism development. International Journal of Tourism Sciences, 18(4), 269-278. https://doi.org/10.1080/15980634.2018.1551312.

27. Scheyvens, R., \& Biddulph, R. (2018). Inclusive tourism development. Tourism Geographies, 20(4), 589-609. https://doi.org/10.1080/14616688.2017.1381985.

28. Schulman, M. D., \& Anderson, C. (1999). The dark side of the force: A case study of restructuring and social capital. Rural Sociology, 64(3), 351-372. https://doi.org/10.1111/j.1549-0831.1999.tb00357.x.

29. Shaw, G. (2014). Tourism networks, knowledge dynamics and co-creation. Knowledge Networks and Tourism, 45, 27-31. https://doi.org/10.4324/9780203768754.

30.Strobl, A., \& Peters, M. (2013). Entrepreneurial reputation in destination networks. Annals of Tourism Research, 40 (January), 59-82. https://doi.org/10.1016/j.annals.2012.08.005.

31.Terpstra, V., \& Simonin, B. L. (1993). Strategic alliances in the triad: an exploratory study. Journal of International Marketing, 4-25. https://doi.org/10.1177/1069031x9300100102.

32. Tregear, A., \& Cooper, S. (2016). Embeddedness, social capital and learning in rural areas: The case of producer cooperatives. Journal of rural studies, 44, 101-110. https://doi.org/10.1016/j.jrurstud.2016.01.011.

33. van der Zee, E., \& Vanneste, D. (2015). Tourism networks unraveled; A review of the literature on networks in tourism management studies. Tourism Management Perspectives, 15(July), 46-56. https://doi.org/10.1016/j.tmp.2015.03.006.

34. Weidenfeld, A. (2013). Tourism and cross border regional innovation systems. Annals of Tourism Research, 42(July), 191-213. https://doi.org/10.1016/j.annals.2013.01.003.

35. Woodhouse, A. (2006). Social capital and economic development in regional Australia: A case study. Journal of rural studies, 22(1), 83-94. https://doi.org/10.1016/j.jrurstud.2005.07.003.

36.Zapata Campos, M. J., Hall, C. M., \& Backlund, S. (2018). Can MNCs promote more inclusive tourism? Apollo tour operator's sustainability work. Tourism Geographies, 20(4), 630-652. https://doi.org/10.1080/14616688.2018.1457074. 